\title{
Longitudinal Jerk and Celeration as Measures of Safety in Bus Rapid Transit Drivers in Tehran
}

\author{
Khorram, B., (1) af Wåhlberg, A. E., (2) \& Tavakoli, A. (1) \\ 1. Iran University of Science and Technology. \\ 2. School of Aerospace, Transport and Management \\ Cranfield University, Cranfield, Bedfordshire, MK43 0AL, UK
}

Accepted for publication in Theoretical Issues in Ergonomics Science

\begin{abstract}
Traditionally, analysis of individual differences in road traffic crash risk has relied on after the fact crash data. Nowadays with the help of technologies like GPS, new measures are developed to assess driving risk, inferred from naturalistic driving behavior of drivers. In this study, two main ways of modelling driver behavior in naturalistic driving research were discussed and compared to each other. For this purpose, 176 Bus Rapid Transit (BRT) drivers were investigated during their normal driving on Tehran BRT routes. Their speed was continuously recorded by a smart phone app from which was derived deceleration, jerk, and celeration measures. Analysis showed that all of the proposed measures had positive correlations with culpable crashes and that one of the jerk variables yielded the highest correlation. Measurements of speed derivatives like jerk and celeration can help to identify dangerous driving styles in public transportation and reduce the number of crashes. Although the results of this study are encouraging, further studies for longer periods are needed to improve the reliability of the measures.
\end{abstract}

KEYWORDS: Driver behavior, Acceleration measures, Bus safety, Crash, Naturalistic driving study

\section{Relevance to human factors/ergonomics theory}

There are two fundamentally different ways of modelling driver behavior in naturalistic driving research, which are not always separated. This paper discusses and compares the two approaches 
of events and means for calculating risk indexes. It also highlights the importance of explicit statements about what assumptions are actually made when different methods are used.

\section{Introduction}

The majority of road crashes are the result of human errors (Lewin, 1982; Mallia, Lazuras, Violani, \& Lucidi, 2015), and individual differences in driving style have been shown to be associated with crashes (af Wåhlberg \& Dorn, 2009; Elander, West, \& French, 1993; Mallia et al., 2015). This leads us to the need to study the role of the human factor in the causing of crashes and to find individual differences regarding traffic safety. With the help of vehicle telematics, new measures could be obtained to explore individual differences concerning crash risk. A number of measures derived from drivers' speed change while driving have been developed in recent naturalistic driving studies (e.g. af Wåhlberg, 2000; 2006; Bagdadi, 2013; Bagdadi \& Várhelyi, 2011; Chen, Yu, Zhu, Chen, \& Li, 2015; Feng et al., 2017; Strauss, Zangenehpour, Miranda-Moreno, \& Saunier, 2017), apparently with the aim of predicting individual differences in crash risk. Two main approaches in such measurements will be used in the present study. The first one will be called the mean-based approach; assuming that all speed changes while driving indicate risk (e.g., driver celeration behavior; af Wåhlberg, 2008a), while the second one could be called an event-based approach, which assumes that risk is only present when a certain threshold has been reached (e.g., jerk rate). These two approaches to naturalistic driving behavior will now be described in more detail.

The mean-based approach originated with Robertson, Winnett, and Herrod (1992), but has been further developed by af Wåhlberg into the theory of Driver Celeration Behavior Theory (DCBT; af Wåhlberg, 2008a). This theory assumes a linear association between absolute acceleration and 
risk of a crash, and that this measure captures all safety-relevant behavior of the driver. Therefore, the mean of absolute acceleration of the driver will be the best possible predictor of the driver's crashes (af Wåhlberg, 2008a). This measure has been applied to a number of bus safety-related studies (af Wåhlberg, 2006; 2007c; 2012) to predict individual differences in traffic safety. Similar calculation methods have been used by Lajunen, Karola, and Summala (1997) and Quimby, Maycock, Palmer, and Grayson (1999) for crash prediction, with some positive results.

In the event-based approach, deceleration rate (DR) is another measure which is the result of braking (i.e., deceleration) of drivers while driving. In the literature, deceleration rate (number of events exceeding a threshold per time) has been used as a measure of safety, especially for the proactive safety assessment of crash-prone locations. Strauss et al. (2017) used smart phone GPS data from cyclists in Montreal to calculate their deceleration behavior while cycling in different parts of the city. The primary hypothesis behind their research was that locations with more high DRs were the ones where more cyclists were injured, and a 0.6 correlation between dangerous sites and deceleration events was found. Many other studies have used rapid deceleration events (usually called 'harsh braking') as a measure indicating individual differences in safety, but with different cut-offs for what was considered dangerous (Albert, Musicant, Lotan, Toledo, \& Grimberg, 2011; Bell, Taylor, Chen, Kirk, \& Leatherman, 2017; Chevalier et al., 2017; Farmer, Kirley, \& McCartt, 2010; Hickman \& Geller, 2005; Strömberg \& Karlsson, 2013; Tapp, Pressley, Baugh, \& White, 2013). However, there is little evidence that this kind of measure is actually related to crash involvement at the level of the individual driver (e.g. Guo, Klauer, Hankey \& Dingus, 2010; Jun, Ogle \& Guensler, 2007; Simons-Morton, Zhang, Jackson \& Albert, 2012). It can also be noted that the method of Pande et al. (2017) theoretically lies somewhere in between the DCBT and the event-based approach. 
Another event-based measure used in naturalistic driving studies is the jerk. Jerk means the rate of change of acceleration, and it could, therefore, be averaged like celeration. However, in research using this measure, it has always been regarded as an event when a certain threshold was exceeded, in similarity to DR. According to some studies, jerkiness in driving could be a measure representing riskier driving behavior (Bagdadi, 2013; Bagdadi \& Várhelyi, 2011; Feng et al., 2017), although no theoretical reasons for this have been given. In a study of 166 private car drivers, drivers with a higher number of jerks had more crashes (Bagdadi \& Várhelyi, 2011). However, the dependent variable in the study was self-reported crashes of drivers, meaning that their results might have been biased (af Wåhlberg, 2002; Maycock, Lockwood, \& Lester, 1991; Wood, Donnell, \& Fariss, 2016) although we do not know in which direction. This problem was addressed in the present study since the crash data used in are from professional Bus Rapid Transfer (BRT) drivers whose crashes are well recorded by the bus company ${ }^{1}$. In similarity to DR, jerky driving has also been used to identify crash-prone locations (Pande et al., 2017).

Previous studies on jerk rate and DR have used different values for thresholds to investigate individual differences, assuming a predefined threshold as an indicator of risky driving. For example, Bagdadi and Várhelyi (2011) assumed $-10 \mathrm{~m} / \mathrm{s}^{3}$ as the threshold for high magnitude jerk, while Pande et al. (2017) used $-2 \mathrm{ft} / \mathrm{s}^{3}$ for their study. Similarly, while Chevalier et al. (2017) used $7.35 \mathrm{~m} / \mathrm{s}^{2}$ as the threshold for DR, Strauss et al. (2017) chose $3.4 \mathrm{~m} / \mathrm{s}^{2}$. Besides, there was a number of other studies that did not assume a single special threshold, and instead considered a number of different cut-off levels (Klauer, Dingus, Neale, Sudweeks, \& Ramsey, 2009; Klauer, Sayer,

\footnotetext{
${ }^{1}$ In the Tehran Bus Company, drivers are instructed to report crashes to the supervisor of the route and also to the Police. The crash descriptions are then manually entered into a computer system by an agent responsible for the crash records in the bus company.
} 
Baynes, \& Ankem, 2016). These differences in cut off levels could be due to the aims of the studies, the data available, groups of drivers studied, but also a lack of proper theory.

In the present study, the aim has been to consider these two approaches (means and events) as ways to model driver behavior in BRT drivers. In previous naturalistic driving behavior studies on bus drivers, mainly celeration behavior of drivers (the mean-based approach) has been discussed, while measures like DR and jerk rate (event-based approaches) have not been investigated. The reverse situation is at hand for car drivers. The present paper is the first study which compares these three variables. Identifying these measures in bus drivers is essential because of the prominent role of this mode in everyday passenger transport (Muhlrad \& Lassarre, 2005). In the United States, in 2016 over 71000 buses were involved in traffic crashes (including fatal, injury and PDO crashes), and the number of fatalities in bus crashes per 100 million vehicle miles travelled was 1.61, which was higher than for passenger vehicles (1.15) (Analysis Division Federal Motor Carrier Safety Administration, 2018). The bus safety issue is even more challenging in developing countries, due to the higher risk of travel by this mode in comparison to developed countries (Barua \& Tay, 2010; Kaplan \& Prato, 2012). In Bangladesh, among all vehicles involved in crashes in urban areas, $17 \%$ are transit buses (Barua \& Tay, 2010). In Ghana, the passengers of buses/minibuses are among the road users with the highest fatality risk (National Road Safety Commission, NRSC, 2014), and buses/minibuses were about $24 \%$ of the total number of vehicles involved in crashes in the period 1991-2014 (Sam, Daniels, Brijs, Brijs, \& Wets, 2018). In Iran, bus transit safety is of high importance because of the popularity of this mode of travel among the majority of people, due to the affordability and accessibility of bus travel (Besharati \& Tavakoli Kashani, 2017). Bus Rapid Transit (BRT) is very popular, especially in Tehran, for those reasons. There are ten routes of BRT in Tehran in service every day. In two of these routes about 600 
crashes were recorded from April 2015 to June 2017. In addition, BRT's higher speed (since they have exclusive lanes in most of their routes) and the higher number of passengers per day (because of their higher capacity) by this mode of travel results in greater risk in comparison to standard transit buses.

Given that driver behavior in terms of speed and its derivatives is posited to be very closely related to crashes (at least in celeration theory; af Wåhlberg, 2008a), it follows that other crash predictors, like age and experience, should be correlated to speed derivatives in a similar way as to how they are correlated with crashes. This should happen because age and experience are internal variables which cause part of the externally visible behavior, which in its turn cause the crashes. This leads to the prediction that the relative strength of correlations of internal variables versus crashes and speed derivatives will be the same (af Wåhlberg, 2018), but also that they will not be significant in a model which takes into account both speed derivatives and other variables, because the former will always explain the same variance in the crash data, but with more power (af Wåhlberg, 2008a). Testing whether age and experience conform to this predicted pattern in the current study is, therefore, a supporting test of the celeration model concerning how speed derivatives relate to crash involvement. Also, it could be expected that younger drivers have more crashes and display more dangerous behavior in terms of speed derivatives, which is also tested.

\section{Method}

\subsection{Objective}

In the present study, using a smart phone app, the speed profiles of a number of BRT drivers were recorded while they were driving in normal traffic conditions. Using recorded crashes as the dependent variable, this study tested deceleration, jerk, and celeration as safety proxy variables. 
For the variable with the highest correlation with crashes, a model was fit to the data to see the measure's effects on crash frequency.

\subsection{Subjects}

The population studied was Tehran BRT drivers, working at two routes of Tehran BRT routes (route $\mathrm{A}$ and $\mathrm{B}$ ). In these two routes about 280 drivers, all male, drive either a morning or an evening shift (6 a.m. to 2 p.m. or 2 p.m. to 10 p.m. A driver usually works one shift only, i.e. there is no regular change between shifts. The drivers have two and a half days off each month. At the terminals, there are facilities for the drivers where they can rest.

Before measurements started, the staff and the drivers of the bus company were informed about the study, but since the drivers did not know the researcher, the assumption was that they would keep driving in their natural driving style, and the presence of the researcher should have had no effect on their behavior. Also, the researcher did not measure anything which is not openly available to anyone riding on the bus. This sample of drivers was a convenience sample, as the researcher entered any bus which happened to arrive at the starting point of measurement. Over 250 measurements were made in February, March, May, and June of 2017. To lessen the effects of environmental factors on driver behaviours (af Wåhlberg, 2007b), almost all of the measurements were made between 7:30 a.m. and 4:00 p.m., because the duration 5:00 p.m. to 9:00 p.m. is the traffic peak period in Tehran (morning peak period in Tehran is 6:30 a.m. to 7:30 a.m.). In addition, no measurement was made during holidays, since holiday traffic differs from normal traffic conditions. In the end, data on a sample of 176 BRT drivers was collected. All drivers on these two routes have more than ten years of service, as only drivers who are experienced in standard transit buses are allowed to drive BRTs. The descriptive statistics for age, years of service, 
crashes and moving time of measurements (for the drivers having more than one measurement, moving time is the average of two or three measurements) of the sample are shown in Table 1.

Table 1. Descriptive statistics of age ${ }^{2}$, experience, crashes and moving time

\begin{tabular}{cccccc}
\hline Measures & Minimum & Maximum & Mean & $\begin{array}{c}\text { Std. } \\
\text { Deviation }\end{array}$ & Variance \\
\hline Age & 35 & 58 & 45.24 & 4.77 & 22.78 \\
\hline Years of service & 11 & 27 & 15.39 & 3.00 & 9.05 \\
\hline Crashes & 0 & 9 & 1.82 & 1.59 & 2.53 \\
\hline $\begin{array}{c}\text { Moving time (total time - stopping time) } \\
\text { (minutes) }\end{array}$ & 14.58 & 36.15 & 23.83 & 5.39 & 29.06 \\
\hline
\end{tabular}

\subsection{Procedure}

The two routes where the research was undertaken both start from the same terminal but end at two different terminals. Route $\mathrm{A}$ is about $13 \mathrm{~km}$ long and route $\mathrm{B}$ about $10 \mathrm{~km}$. Both directions in each of these routes are almost the same. The difference between the distances of the two ways in route $\mathrm{A}$ is less than $5 \%$ of the whole length of the route. The speed limit for both routes is 50 $\mathrm{km} / \mathrm{h}$. The method used in this study for data gathering was similar to the study by af Wåhlberg (2000). The researcher entered a bus at one of the three terminals (one is shared between routes), and sat on the last seat at the rear of the bus, then started recording the speed until the bus stopped at the other terminal. Then the identity of each driver was determined from the bus company's

\footnotetext{
${ }^{2}$ Age and experience data of 16 drivers were not available in the list the authors were provided by the department of bus company which is responsible for route A and B, which could be due to driver transfers from other BRT routes. The statistics of age and experience in Table 1 and further analysis of age data were therefore based on 160 drivers.
} 
duty list (based on plate number, date and time). All of the BRT buses were of the same type (Yutong). The instrument used in this study to record the speed of drivers was a smart phone (Huawei Ascend) app which recorded speed at each second $(1 \mathrm{~Hz})$. Using smart phones for data gathering in research is getting more popular, as they are easy to use and can record data in a sophisticated manner (Blanc \& Figliozzi, 2017; Guido et al., 2012; Picone, Amoretti, \& Zanichelli, 2012; Strauss et al., 2017; Vaiana et al., 2014). Today some of the smart phones use a combination of different $\mathrm{GNSS}^{3} \mathrm{~s}$ which could improve the accuracy of positioning, due to more satellites being available in comparison to standalone GPS (Angrisano, Gaglione, \& Gioia, 2013; Mohammed, Moore, Hill, Bingley, \& Hansen, 2016). The smart phone used in this study took advantage of a combination of GNSSs, including GPS, A-GPS, and GLONASS.

\subsection{Editing data}

In some of the measurements, a few seconds of speed data were not recorded, because of low signals from the GPS or app malfunction. In the deceleration calculations this could cause spurious values; therefore all the records of each measurement were scrutinized in search of GPS gaps. If in a portion of data one second or more was lost, DR or jerk rate measures related to that part of the measurement were not counted. Records which had more than a few seconds data lost were deleted from the sample. About 10 percent of the total measurements were removed from the sample due to this reason.

\subsection{Crash data}

Crash data were acquired from Tehran Bus Company from April 2015 to June 2017. All of the sample's drivers had been working during this period. In addition to the drivers' name each record

\footnotetext{
${ }^{3}$ Global Navigation Satellite System
} 
in these crash data is accompanied by two more fields, the location of the crash (i.e., whether the crash had occurred while the driver was in route or terminal or at a bus repair shop) and a description of the crash (mentioning whether the driver was culpable or not based on a police report, and also an explanation about the crash). Crash data before the date mentioned above are not accompanied by those two extra fields and are therefore unreliable. Descriptive statistics of crashes are presented in Table 1.

The crashes that happened in terminals or other places except the route were deleted because they could be related to maintenance, refuelling or even poor design of terminals (causing difficulties for buses to stand in a queue) rather than driver behavior (Strathman, Wachana, \& Callas, 2010). In addition, in this study, drivers' behavior was only studied while they were driving between terminals. The original number of crashes was about 1650 , of which about 40 percent happened on-route. Some of the other records that did not include a collision (e.g., front glass break after being hit by a rock) were also deleted. Furthermore, only the culpable crash records were used, while non-culpable crashes were deleted. These were about five percent of the on-route crashes. There are a number of studies which have used culpable crashes only as the dependent variable in bus driver safety studies (af Wåhlberg, 2004; Goh, Currie, Sarvi, \& Logan, 2014; Tseng, 2012). As could be expected (af Wåhlberg \& Dorn, 2007; Dorn \& af Wåhlberg, 2018) it has been found in some studies that culpable crashes have a higher correlation with predictors than all crashes (af Wåhlberg, 2008b; Arthur, Strong, \& Williamson, 1994; Gully, Whitney, \& Vanosdall, 1995; see af Wåhlberg, 2009 for a review). The number of drivers in the sample with their respective number of crashes is shown in Table 2.

Table 2. Number of drivers in each crash category

\begin{tabular}{cc}
\hline Number of Crashes & Number of drivers \\
\hline Zero & 37
\end{tabular}




\begin{tabular}{cc}
\hline One & 45 \\
\hline Two & 50 \\
\hline Three & 21 \\
\hline Four & 12 \\
\hline Five & 6 \\
\hline Six & 3 \\
\hline Seven & 0 \\
\hline Eight & 1 \\
\hline Nine & 1 \\
\hline Total number of crashes & 321 \\
\hline
\end{tabular}

\subsection{Explanatory variables}

The speed data were used to compute acceleration between every two consecutive records, using equation 1 :

$$
a=\frac{d v}{d t}
$$

In equation 1 , a is acceleration $\left(\mathrm{m} / \mathrm{s}^{2}\right) ; d v$ is the change in speed between two consecutive points $(\mathrm{m} / \mathrm{s}) ; d t$ is the change in time between two consecutive points (s);

Thereafter accelerations were used to compute jerks (j), deceleration (DR) and celeration:

$$
j=\frac{d a}{d t}
$$

$\mathrm{j}$ is jerk $\left(\mathrm{m} / \mathrm{s}^{3}\right)$; $d a$ is the change in acceleration $\left(\mathrm{m} / \mathrm{s}^{2}\right)$. This method of calculating acceleration and jerk is similar to those in previous studies (Pande et al., 2017; Strauss et al., 2017).

As mentioned before, this study assumes that the drivers who tend to cause more harsh braking events would have more crashes, but to measure these situations a proper threshold in deceleration or jerk is needed. Since no theoretical reason for choosing a certain threshold for retaining jerks as significant events had been found, several different classifications of thresholds for both decelerations and jerks were tested. 
A set of thresholds were used for deceleration, defined as follows:

$\mathrm{d} \_\mathrm{x}$; number of all critical decelerations that are equal or below threshold $-\mathrm{x} \mathrm{m} / \mathrm{s}^{2}$ (e.g., $\mathrm{d} \_2$ meaning sum of deceleration events equal or less than $-2 \mathrm{~m} / \mathrm{s}^{2}$ )

The threshold values which were tested in this study, are 2, 3, 4, 5 and $6 \mathrm{~m} / \mathrm{s}^{2}$. Higher thresholds have been used for other groups of drivers in previous studies (Bagdadi \& Várhelyi, 2011; Chevalier et al., 2017), but for this group of drivers, higher thresholds yielded very low frequencies and even zero events.

The same thresholds were used for jerks and are defined as follows:

j_x; number of all critical jerks that are equal or below $-\mathrm{x} \mathrm{m} / \mathrm{s}^{3}$

The jerk rate and DR measures were gained from two routes with different lengths. Therefore, to hold exposure constant (Bagdadi \& Várhelyi, 2011), the sum of deceleration and jerk measure of each measurement was divided by the length of the route it was recorded on.

To compute celeration, the mean of absolute values of accelerations while speed was greater than zero was calculated for each driver. Since this sample was a convenience sample, some of the drivers were repetitively measured 2 or 3 times ( 42 drivers were measured two times, and eight were measured three times). Repetitive measurements were used to average the measures, as this could improve the reliability of the measure (af Wåhlberg, 2000; 2007a).

\subsection{Statistical analysis}

First, correlation coefficients were calculated to observe the variables' correlation with the crashes and to find the one with the strongest association. Based upon those results, a model was fitted to the data to see the measure's effects on crash frequency. Since crashes are count variables (i.e., they're non-negative integers) they can be modelled with count models. Negative Binomial and Poisson regression models are the most popular models for count data modelling (Washington, 
Karlaftis, \& Mannering, 2010). For this study, a Negative Binomial model was used, since the variance of the crash data was greater than the mean (descriptive statistics of crash data is shown in Table 1), and such over-dispersion violates the assumptions of the Poisson count model (Coruh, Bilgic, \& Tortum, 2015; Miaou, 1994; Washington et al., 2010). Also, the dispersion parameter was significantly greater than zero $(\mathrm{Z}=1.683, \rho-$ value $=0.046)$ meaning that using a Poisson regression would be incorrect. The Negative Binomial model is a modified version of Poisson model which addresses the problem of over-dispersion in data (Dereli \& Erdogan, 2017). Also, to investigate if there was any statistical difference between age groups regarding the number of crashes and critical jerks, Kruskal-Wallis and Mann-Whitney tests were conducted. For statistical calculations, the SPSS 21 software was used.

\section{Results}

\subsection{Descriptive values}

As can be seen in Table 1, drivers tended to be middle-aged and very experienced. Descriptive values of the explanatory variables are displayed in Table 3. As could be expected, the means and standard deviations differed a lot between different threshold levels for jerks and deceleration rates.

\subsection{Correlation analysis}

The correlation coefficients were calculated between number of crashes, celeration, DR and jerk rate, at five thresholds that were described in the Explanatory variables' section. The descriptive statistics of the variables are presented in Table 3. Minimum and maximum numbers for DR and jerk rate in Table 3 show the number of times which a certain threshold was exceeded divided by length of the route $(\mathrm{km})\left(\right.$ e.g., d_2 means number of times that deceleration was less than $-2 \mathrm{~m} / \mathrm{s}^{2}$ 
divided by the length of the route, and j_4 shows number of times that jerk was less than $-4 \mathrm{~m} / \mathrm{s}^{3}$ divided by the length of the route), and for celeration, they show the mean of absolute values of acceleration when the vehicle is moving.

Table 3. Descriptive statistics of DR, jerk rate and celeration measures.

\begin{tabular}{|c|c|c|c|c|c|c|}
\hline Measures & Minimum & Maximum & Mean & Std. Deviation & Skewness & Kurtosis \\
\hline \multicolumn{7}{|l|}{ Deceleration } \\
\hline$d \_2$ & 0 & 2.846 & 0.909 & 0.546 & 0.750 & 0.358 \\
\hline$d \_3$ & 0 & 1.000 & 0.172 & 0.167 & 1.854 & 5.126 \\
\hline$d \_4$ & 0 & 0.385 & 0.041 & 0.060 & 2.119 & 6.852 \\
\hline$d \_5$ & 0 & 0.200 & 0.011 & 0.033 & 3.846 & 16.438 \\
\hline$d \_6$ & 0 & 0.200 & 0.002 & 0.017 & 9.392 & 97.462 \\
\hline \multicolumn{7}{|l|}{ Jerk } \\
\hline$j \_2$ & 0 & 4.500 & 1.224 & 0.835 & 1.394 & 2.333 \\
\hline$j_{-} 3$ & 0 & 1.692 & 0.295 & 0.263 & 1.910 & 5.466 \\
\hline$j_{-} 4$ & 0 & 0.600 & 0.091 & 0.105 & 1.643 & 4.049 \\
\hline$j \_5$ & 0 & 0.400 & 0.031 & 0.058 & 2.627 & 9.915 \\
\hline$j \_6$ & 0 & 0.200 & 0.012 & 0.035 & 3.134 & 10.439 \\
\hline Celeration & 0.304 & 0.599 & 0.432 & 0.055 & 0.272 & 0.072 \\
\hline
\end{tabular}

Table 3 shows the descriptive statistics of each threshold of DR and jerk rate measures and also the celeration measure, which are inferred from the whole sample (meaning the measures were calculated for each driver).

The correlation results between variables and crashes are shown in Table 4:

Table 4. The Pearson correlations between the crash number and DR, jerk rate and celeration.

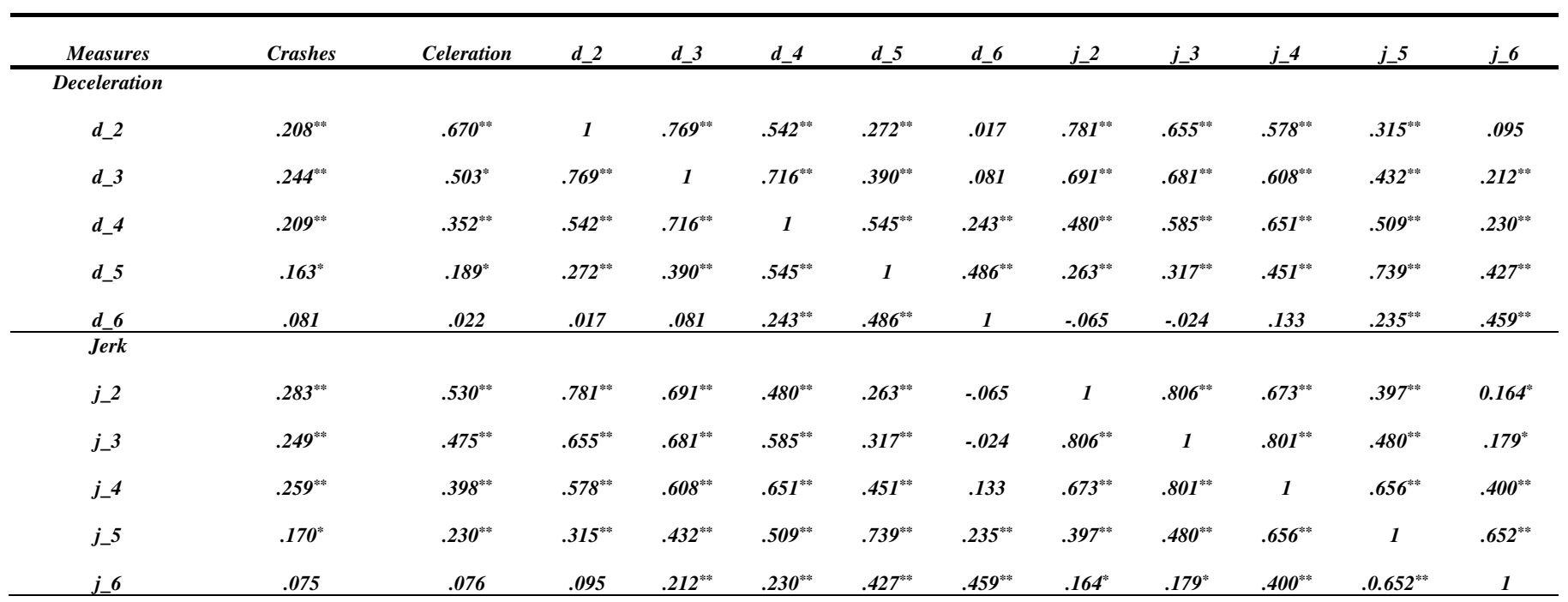


Table 4 reports correlation results between speed change measures and crashes for the whole sample, 176 drivers. Celeration and different thresholds of DR and jerk rate measures all had positive correlations with crashes. For the DR measure, the thresholds $-2 \mathrm{~m} / \mathrm{s}^{2},-3 \mathrm{~m} / \mathrm{s}^{2},-4 \mathrm{~m} / \mathrm{s}^{2}$, and $-5 \mathrm{~m} / \mathrm{s}^{2}$ had significant correlations with crashes. There were positive inter-correlations between different thresholds of the DR measure with all other variables, and most of these correlations were significant. For the jerk rate measure the correlation with crashes for thresholds $-2,-3,-4$, and $-5 \mathrm{~m} / \mathrm{s}^{3}$ was significant. Celeration also had a positive significant correlation with crashes and positive, mostly significant, correlations with all other measures. Among decelerations and jerks, jerks in all of the thresholds except $-6 \mathrm{~m} / \mathrm{s}^{3}$ showed higher correlations in comparison to the deceleration threshold of the same number (e.g., $\mathrm{j} \_2$ correlation, in comparison to $d \_2$ correlation). Since more than one threshold was used for each of jerk rate and DR, the mean of thresholds' correlation for each measure was compared with celeration. The average correlations of DR and jerk rate were 0.181 and 0.207 respectively, while the value of celeration was 0.183 . The averaged values of DR and jerk rate measures were thus very similar to that of celeration. Among all of the jerk measures, the threshold $-2 \mathrm{~m} / \mathrm{s}^{3}$ had the highest correlation with crashes and was used for crash frequency modelling in the next section.

Also, the reliability of measurements for celeration in this study was calculated. The correlation between first and second measurements was calculated to see how much they agreed within drivers (af Wåhlberg, 2004). Results show a $0.351(\mathrm{n}=42, \rho-$ value $=0.022)$ correlation between these variables. 


\subsection{Crash frequency modelling}

Thereafter, negative binomial regression modelling with crashes as dependent variable was undertaken. The explanatory parameters were jerk rate, continuous age and experience variables, and a variable defining route (showing from which route data was gathered).

In the first model, only the jerk rate was significant. Experience showed a negative coefficient, meaning the more experienced drivers had fewer crashes, and age had a positive coefficient showing the more aged, the more crashes, but none of these two was a significant contributor to the model. The route variable also was not significant, which could be expected since the means of crashes were very similar between these two routes (this was statistically tested, route 1, mean rank $=87.21$ - route 2, mean rank $=90.02, p$-value $=0.708$ not significant $)$. The continuous variable of age was not significant. However, age can be expected to have a non-linear effect on crashes. Therefore, the age of drivers was classified into four categories: 35-40 (group 1), 41-46 (group 2), 47-52 (group 3), and 53-58 (group 4) and then added as a group variable in a new model. The boundaries of age categories were chosen on the basis of previous studies and available age of drivers in the sample. The number of drivers in the age groups is shown in Table 5.

Table 5. Number of drivers in each age group

\begin{tabular}{cc}
\hline Age & Drivers \\
\hline 35-40 (Group 1) & 27 \\
$41-46($ Group 2) & 72 \\
$47-52($ Group 3) & 49 \\
$53-58($ Group 4) & 12 \\
\hline Total & 160
\end{tabular}

Another model, inclusive of jerk rate and the age group variable was tested. Again, the age variable was not significant. Variables with no explanatory value (i.e., $p-$ value $>0.05$ ) were excluded from the model. The final model results are presented in Table 6 . 
Table 6. Final Negative binomial model results (age, experience, and the route variable were excluded)

\begin{tabular}{cccc}
\hline Variables & $\beta-$ Coefficient $(95 \% C I)$ & $E X B(\beta)(95 \% C I)$ & $p-$ value \\
\hline Jerk-rate $\left(j_{2} 2\right)$ & $0.253(0.122-0.384)$ & $1.287(1.129-1.468)$ & 0.000 \\
Intercept & $0.267(0.049-0.485)$ & & \\
\hline
\end{tabular}

The results of the final model based on 176 drivers show a positive significant 0.253 coefficient for the jerk $\left(\mathrm{j}_{-} 2\right)$ parameter. The model implies that for each additional jerk per kilometre, the number of crashes of that driver increases by $28.7 \%$.

Although the age groups showed no statistically significant effect on the expected number of crashes based on the Negative binomial regression model, a non-parametric Kruskal-Wallis test was computed as a separate test. The result of this test was also not significant $(p-$ value $>0.7)$, meaning there is no statistical difference in crashes between these age groups.

Also, it could be interesting to see if there is any statistical difference between age groups in terms of causing critical jerks. Younger drivers could be expected to cause more jerks and subsequently to have more crashes, but in the case of present study no difference in crashes was found which could be due to the small number of drivers and also because of the fact that crashes are rare events that need a larger sample of drivers and a wider range of age, including very young drivers, to show the effect. However, a difference in jerky driving would be easier to detect. To test this, a Kruskal-Wallis test was conducted to consider if there was any statistical difference in terms of the number of jerks between these age groups. The result shows that there was no statistical difference between age groups concerning the jerk either $(p-$ value $=0.950)$. This was also tested for the jerk rate threshold $-4 \mathrm{~m} / \mathrm{s}^{3}$, which had the second highest correlation with crashes 
after $\mathrm{j} \_2$. This time a significant difference between age groups was found ( $p-$ value $\left.=0.024\right)$. To consider differences between each two age groups, Mann-Whitney tests were conducted.

The results show that age group one (i.e. 35-40 year old drivers) caused significantly more high jerks (based on $\mathrm{j}_{-} 4$ threshold) than age group two (mean rank group $1=62.65$, mean rank group $2=45.26, p-$ value $=0.006$ ). Also the results show that age group one made significantly more jerks than group three (mean rank group $1=45.59$, mean rank group $3=34.59, p-$ value $=$ 0.034), and even group one caused significantly more jerks than group four (mean rank group $1=$ 22.74, mean rank group $4=13.83, p-$ value $=0.022$ ). No significant differences were found between age groups two with three $(p-$ value $=0.492)$, two with four $(p-$ value $=0.458)$, and three with four $(p-$ value $=0.265)$.

\section{Discussion}

\subsection{Results}

This study aimed to consider two main ways of modelling driver behavior. For this, three speedchange derivative measures taken from naturalistic driving were investigated, and their associations with crashes of each driver were calculated. Among these measures, celeration has been investigated previously in bus drivers, while DR and jerk rate were analyzed for the first time for this type of driver. The correlation results showed that in almost all of the jerk rate measures (except the $-6 \mathrm{~m} / \mathrm{s}^{3}$ threshold) there were higher correlations with crashes than for the DR measures. Results also showed that the celeration measure had a positive and significant correlation with crashes. It can be noted that as cut-off levels (thresholds) in jerk measures were set lower, this measurement approached the mean (celeration) method, as is also shown by the increasing correlation with this variable. It can, therefore, be predicted that crash involvement prediction will improve as thresholds for events are lowered, as is evident in the present study. 
However, this effect is difficult to evaluate, because events tend to become very uncommon at higher thresholds, meaning that restriction of variance will influence the effect sizes.

Correlation results showed that three of the jerk measures had higher correlation with crashes than the celeration measure, and also the mean of jerk measures' correlations was higher than celeration's, so jerk was chosen as the explanatory variable for the count regression model. The final regression count model only included the jerk variable as explanatory. As expected, the route variable was not significant, due to the similarity of crash numbers between the routes. Also, the model found that the effect of age on crashes was not significant. The final model shows a positive relationship between the rate of jerks caused by a driver and his crashes. Although the age variable was not significant in crash prediction, its effect in terms of the rates of jerks in different age groups was tested. Based on a threshold of $-4 \mathrm{~m} / \mathrm{s}^{3}\left(\mathrm{j}_{-} 4\right)$, a significant difference was found. It could be expected that younger drivers cause significantly more critical jerks in comparison to older drivers, due to their higher risk of crashing, and this result was in agreement with the finding of a previous study (Bagdadi, 2013).

The present study used no specific threshold of time for identifying events, only the sheer magnitude of difference at $1 \mathrm{~Hz}$ of measurement. This mean that the number of events would have been different if, for example, a criterion of two seconds duration had been applied. Similarly, if the frequency of measurement had been different, the values would have been too. As this kind of information is usually not given in naturalistic driving studies, it is therefore not really possible to compare the current results with others.

4.2 Limitations and suggestions for further research 
This study used an average of about 24 minutes of driving (moving time) for each driver which yielded a 0.35 correlation between measurements for the celeration variable which is not a very high reliability. Although there are previous studies that have used about the same duration of measurements (af Wåhlberg, 2000; 2004) for bus drivers, low reliability could be a limitation for this study. For future studies, longer periods of study are recommended, as predictive power versus crashes increase with longer measurements (af Wåhlberg, 2007a).

A methodological difficulty in this kind of research which must be acknowledged is that the eventbased and the mean-based variables can be expected to correlate rather heavily, as was seen in the present study. This could be due to the sharing of in-data (common method variance), and that they measure parts of the same behavior syndrome. Statistical power to detect any differences (in crash prediction) will therefore be low, and rather large samples will be needed to test which approach is superior.

Another limitation of this study was that effects of gender were not studied. In previous naturalistic driving studies, gender effects in braking events have been discussed, for example Bagdadi (2013) found the effects of gender not significant in causing critical jerks while Montgomery, Kusano, and Gabler (2014) found a statistical difference in terms of time to collision (TTC) at onset of braking between men and women. If any difference between men and women in terms of crash risk does exist for a certain population, it should also be measurable as events and celeration behaviour. Although in Iran female drivers, especially in BRTs, are scarce, considering the effects of gender on crashes and acceleration behavior is recommended in future studies.

\subsection{Conclusions}


As stated in the introduction, the majority of telematics research studies (including jerk studies) do not use an over-arching theory, or even test explicit hypotheses. The only exception is the celeration theory of af Wåhlberg (2008a). However, given the tenets of that theory, and the quasitheoretical properties of event detection as described in various naturalistic driving studies, the results of the current study can still be considered for what they mean in terms of theory. First, there is one curious discrepancy in the results of this study; although predictive power versus crashes was higher for low threshold deceleration events than for high thresholds, the mean of these was still higher than the effect for celeration. This is strange, because as the threshold for events is lowered, the event variable becomes more similar to the celeration parameter. Therefore, celeration should have the higher predictive power, as predicted by the DCBT. Why this did not happen in these data, and the pattern of effects just described, is therefore in need of a theoretical explanation. This could for example be couched in terms of a theory in which events of a certain threshold are more strongly associated with crashes than those of other thresholds. Currently, naturalistic driving studies use no theory, and any kind of threshold, and it is therefore not really possible to know what the results mean.

For the DCBT, the results were positive in terms of showing, again, a positive correlation between this variable and crash involvement. On the other hand, the prediction of a higher coefficient for this variable than for events was not upheld. However, it is still too early to conclude whether the theory needs to be revised. More studies are needed before it can be said with certainty whether results are in line with predictions.

Age and experience were not significant predictors in a statistical model which included one of the jerk variables. This is in line with the prediction from the DCBT, but it is not a good test of the hypothesis, because age and experience were very weakly associated with crash involvement 
anyway. This lack of association was probably due to low variance in this population of selected drivers. Also, age might be non-linearly correlated with crash involvement, even in this population without very old drivers.

In a wider theoretical sense, the present analyses and results indicate that the undertaking of measuring safety-related driver behaviour is not an easy task, as results may differ a lot due to exactly how the variable is specified when it is extracted from the raw speed/time data. It can be noted that this measurement problem is hardly ever considered in papers about naturalistic driving and similar topics (e.g. Birrell, Young, Jenkins \& Stanton, 2012; Engström et al., 2017; Jeon, 2015; Ljung Aust \& Engström, 2011; Pampel et al., 2018).

For this study, a smart phone was used by a researcher to gather data which was very timeconsuming. In future studies, smart phone data from regular bus passengers could be used. For most companies it is also possible to use the telematics system which records speed data of the vehicle, although some vendors are reluctant to share the raw data.

Finally, this study could be helpful to bus companies and bus safety administrators in allowing for methods of discovering and lessening dangerous behaviours by the drivers by better monitoring of their performance regarding their deceleration and acceleration behaviours. Since the data in this study was gathered from a smart phone, which is a very common and available device among people, the results of this study could be further extended and lead to more reliable measures.

\section{References}

af Wåhlberg, A. E. (2000). The relation of acceleration force to traffic accident frequency: a pilot study. Transportation Research Part F: Traffic Psychology and Behaviour, 3, 29-38. 
af Wåhlberg, A. E. (2002). On the validity of self-reported traffic accident data E140 Proceedings of Soric 02 .

af Wåhlberg, A. E. (2004). The stability of driver acceleration behavior, and a replication of its relation to bus accidents. Accident Analysis \& Prevention, 36, 83-92.

af Wåhlberg, A. E. (2006). Speed choice versus celeration behavior as traffic accident predictor. Journal of Safety Research, 37, 43-51.

af Wåhlberg, A. E. (2007a). Aggregation of driver celeration behavior data: Effects on stability and accident prediction. Safety Science, 45, 487-500.

af Wåhlberg, A. E. (2007b). Effects of passengers on bus driver celeration behavior and incident prediction. Journal of Safety Research, 38, 9-15.

af Wåhlberg, A. E. (2007c). Long-term prediction of traffic accident record from bus driver celeration behavior. International Journal of Occupational Safety and Ergonomics, 13, 159-171.

af Wåhlberg, A. E. (2008a). Driver celeration behaviour and accidents-an analysis. Theoretical Issues in Ergonomics Science, 9, 383-403.

af Wåhlberg, A. E. (2008b). The relation of non-culpable traffic incidents to bus drivers' celeration behavior. Journal of Safety Research, 39, 41-46.

af Wåhlberg, A. E. (2009). Driver Behaviour and Accident Research Methodology; Unresolved Problems. Farnham: Ashgate.

af Wåhlberg, A. E. (2012). Changes in driver celeration behaviour over time: Do drivers learn from collisions? Transportation Research Part F: Traffic Psychology and Behaviour, 15, 471-479.

af Wåhlberg, A. E. (2018). Comparisons of predictive power for traffic accident involvement; celeration behavior versus age, sex, ethnic origin and experience. Safety, 4, 59, https://www.mdpi.com/2313-576X/4/4/59.

af Wåhlberg, A. E., \& Dorn, L. (2007). Culpable versus non-culpable traffic accidents; what is wrong with this picture? Journal of Safety Research, 38, 453-459.

af Wåhlberg, A. E., \& Dorn, L. (2009). Bus driver accident record: the return of accident proneness. Theoretical Issues in Ergonomics Science, 10, 77-91.

Albert, G., Musicant, O., Lotan, T., Toledo, T., \& Grimberg, E. (2011). Evaluating changes in the driving behavior of young drivers a few years after licensure using in-vehicle data recorders. 
In Proceedings of the Sixth International Driving Symposium on Human Factors in Driver Assessment, Training and Vehicle Design, pp. 337-343.

Analysis Division Federal Motor Carrier Safety Administration (2018). Large Truck and Bus Crash Facts 2016. https://www.fmcsa.dot.gov/sites/fmcsa.dot.gov/files/docs/safety/dataand-statistics/398686/ltbcf-2016-final-508c-may-2018.pdf.

Angrisano, A., Gaglione, S., \& Gioia, C. (2013). Performance assessment of GPS/GLONASS single point positioning in an urban environment. Acta Geodaetica et Geophysica, 48, 149161.

Arthur, W., Strong, M. H., \& Williamson, J. (1994). Validation of a visual attention test as a predictor of driving accident involvement. Journal of Occupational and Organizational Psychology, 67, 173-182.

Bagdadi, O. (2013). Assessing safety critical braking events in naturalistic driving studies. Transportation Research Part F: Traffic Psychology and Behaviour, 16, 117-126.

Bagdadi, O., \& Várhelyi, A. (2011). Jerky driving—an indicator of accident proneness? Accident Analysis \& Prevention, 43, 1359-1363.

Barua, U., \& Tay, R. (2010). Severity of urban transit bus crashes in Bangladesh. Journal of Advanced Transportation, 44, 34-41.

Bell, J. L., Taylor, M. A., Chen, G.-X., Kirk, R. D., \& Leatherman, E. R. (2017). Evaluation of an in-vehicle monitoring system (IVMS) to reduce risky driving behaviors in commercial drivers: Comparison of in-cab warning lights and supervisory coaching with videos of driving behavior. Journal of Safety Research, 60, 125-136.

Besharati, M. M., \& Tavakoli Kashani, A. (2017). Factors contributing to intercity commercial bus drivers' crash involvement risk. Archives of Environmental \& Occupational Health,73, 1-8. doi: $10.1080 / 19338244.2017 .1306478$

Birrell, S. A., Young, M. S., Jenkins, D. P., \& Stanton, N. A. (2012). Cognitive Work Analysis for safe and efficient driving. Theoretical Issues in Ergonomics Science, 13, 430-449. doi:10.1080/1463922x.2010.539285 
Blanc, B., \& Figliozzi, M. (2017). Safety Perceptions, Roadway Characteristics, and Cyclists' Demographics: A Study of Crowdsourced Smartphone Bicycle Safety Data. Transportation Research Board $96^{\text {th }}$ Annual Meeting.

Chen, Z., Yu, J., Zhu, Y., Chen, Y., \& Li, M. (2015). D 3: Abnormal driving behaviors detection and identification using smart phone sensors. Paper presented at the Sensing, Communication, and Networking (SECON), 2015 12th Annual IEEE International Conference on.

Chevalier, A., Coxon, K., Chevalier, A. J., Clarke, E., Rogers, K., Brown, J., . . Keay, L. (2017). Predictors of older drivers' involvement in rapid deceleration events. Accident Analysis \& Prevention, 98, 312-319.

Coruh, E., Bilgic, A., \& Tortum, A. (2015). Accident analysis with aggregated data: The random parameters negative binomial panel count data model. Analytic Methods in Accident Research, 7, 37-49.

Dereli, M. A., \& Erdogan, S. (2017). A new model for determining the traffic accident black spots using GIS-aided spatial statistical methods. Transportation Research Part A: Policy and Practice, 103, 106-117.

Dorn, L., \& af Wåhlberg, A. E. (2018). Behavioural culpability for traffic accidents. Transportation Research Part F: Traffic Psychology and Behaviour, 60, 505-514.

Elander, J., West, R., \& French, D. (1993). Behavioral correlates of individual differences in roadtraffic crash risk: An examination of methods and findings. Psychological Bulletin, 113, 279-294.

Engström, J., Bärgman, J., Nilsson, D., Seppelt, B., Markkula, G., Piccinini, G. B., \& Victor, T.

(2017). Great expectations: a predictive processing account of automobile driving. Theoretical

Issues in Ergonomics Science, 19, 156-194. doi:10.1080/1463922x.2017.1306148

Farmer, C. M., Kirley, B. B., \& McCartt, A. T. (2010). Effects of in-vehicle monitoring on the driving behavior of teenagers. Journal of Safety Research, 41, 39-45.

Feng, F., Bao, S., Sayer, J. R., Flannagan, C., Manser, M., \& Wunderlich, R. (2017). Can vehicle longitudinal jerk be used to identify aggressive drivers? An examination using naturalistic driving data. Accident Analysis \& Prevention, 104, 125-136. 
Goh, K., Currie, G., Sarvi, M., \& Logan, D. (2014). Factors affecting the probability of bus drivers being at-fault in bus-involved accidents. Accident Analysis \& Prevention, 66, 20-26.

Guido, G., Vitale, A., Astarita, V., Saccomanno, F., Giofré, V. P., \& Gallelli, V. (2012). Estimation of safety performance measures from smart phone sensors. Procedia-Social and Behavioral Sciences, 54, 1095-1103.

Gully, S. M., Whitney, D. J., \& Vanosdall, F. E. (1995). Prediction of police officers' traffic accident involvement using behavioral observations. Accident Analysis \& Prevention, 27, 355-362.

Guo, F., Klauer, S. G., Hankey, J. M., \& Dingus, T. A. (2010). Using near-crashes as a crash surrogate for naturalistic driving studies. Transportation Research Record, 2147, 66-74.

Hickman, J. S., \& Geller, E. S. (2005). Self-management to increase safe driving among shorthaul truck drivers. Journal of Organizational Behavior Management, 23, 1-20.

Jeon, M. (2015). Towards affect-integrated driving behaviour research. Theoretical Issues in

Ergonomics Science, 16, 553-585. doi:10.1080/1463922x.2015.1067934

Jun, J., Ogle, J., \& Guensler, R. (2007). Relationships between crash involvement and temporalspatial driving behavior activity patterns using GPS instrumented vehicle data. In TRB 2007 annual meeting CD-ROM.

Kaplan, S., \& Prato, C. G. (2012). Risk factors associated with bus accident severity in the United States: A generalized ordered logit model. Journal of Safety Research, 43, 171-180.

Klauer, S. G., Dingus, T. A., Neale, V. L., Sudweeks, J. D., \& Ramsey, D. J. (2009). Comparing

Real-World Behaviors of Drivers with High Versus Low Rates of Crashes and Near-Crashes.

Report DOT HS 811 091. Washington: National Highway Traffic Safety Administration.

Klauer, S. G., Sayer, T. B., Baynes, P., \& Ankem, G. (2016). Using real-time and post hoc feedback to improve driving safety for novice drivers. Paper presented at the Proceedings of the Human Factors and Ergonomics Society Annual Meeting.

Lajunen, T., Karola, J., \& Summala, H. (1997). Speed and acceleration as measures of driving style in young male drivers. Perceptual and Motor Skills, 85, 3-16.

Lewin, I. (1982). Driver training: a perceptual-motor skill approach. Ergonomics, 25, 917-924. 
Ljung Aust, M., \& Engström, J. (2011). A conceptual framework for requirement specification and evaluation of active safety functions. Theoretical Issues in Ergonomics Science, 12, 44-65. doi:10.1080/14639220903470213

Mallia, L., Lazuras, L., Violani, C., \& Lucidi, F. (2015). Crash risk and aberrant driving behaviors among bus drivers: the role of personality and attitudes towards traffic safety. Accident Analysis \& Prevention, 79, 145-151.

Maycock, J., Lockwood, C., \& Lester, J. F. (1991). The Accident Liability of Car Drivers. TRRL

Research Report No. 315. Crowthorne: Transport and Road Research Laboratory.

Miaou, S.-P. (1994). The relationship between truck accidents and geometric design of road sections: Poisson versus negative binomial regressions. Accident Analysis \& Prevention, 26, 471-482.

Mohammed, J., Moore, T., Hill, C., Bingley, R., \& Hansen, D. (2016). An assessment of static precise point positioning using GPS only, GLONASS only, and GPS plus GLONASS. Measurement, 88, 121-130.

Montgomery, J., Kusano, K. D., \& Gabler, H. C. (2014). Age and gender differences in time to collision at braking from the 100-car naturalistic driving study. Traffic Injury Prevention, 15(sup1), S15-S20.

Muhlrad, N., \& Lassarre, S. (2005). Systems approach to injury control. The way forward: transportation planning and road safety. New Delhi, Macmillan India Ltd, 52-73.

National Road Safety Commission (2014). Road Traffic Crashes in Ghana. Accra: NRSC.

Pampel, S. M., Large, D. R., Burnett, G., Matthias, R., Thompson, S., \& Skrypchuk, L. (2019).

Getting the driver back into the loop: the quality of manual vehicle control following long and short non-critical transfer-of-control requests: TI:NS. Theoretical Issues in Ergonomics Science, 1-19. doi:10.1080/1463922x.2018.1463412

Pande, A., Chand, S., Saxena, N., Dixit, V., Loy, J., Wolshon, B., \& Kent, J. D. (2017). A preliminary investigation of the relationships between historical crash and naturalistic driving. Accident Analysis \& Prevention, 101, 107-116. 
Picone, M., Amoretti, M., \& Zanichelli, F. (2012). A Decentralized Smartphone Based Traffic Information System. Paper presented at the Intelligent Vehicles Symposium (IV), 2012 IEEE.

Quimby, A., Maycock, G., Palmer, C., \& Grayson, G. (1999). Drivers'Speed Choice: An In-Depth Study. TRL Report 326. Crowthorne: Transport Research Laboratory.

Robertson, D., Winnett, M., \& Herrod, R. (1992). Acceleration signatures. Traffic Engineering \& Control, 33, 485-491.

Sam, E. F., Daniels, S., Brijs, K., Brijs, T., \& Wets, G. (2018). Modelling public bus/minibus transport accident severity in Ghana. Accident Analysis \& Prevention, 119, 114-121.

Simons-Morton, B. G., Zhang, Z., Jackson, J. C., \& Albert, P. S. (2012). Do elevated gravitationalforce events while driving predict crashes and near crashes? American Journal of Epidemiology, 175, 1075-1079.

Strathman, J. G., Wachana, P., \& Callas, S. (2010). Analysis of bus collision and non-collision incidents using transit ITS and other archived operations data. Journal of Safety Research, $41,137-144$.

Strauss, J., Zangenehpour, S., Miranda-Moreno, L. F., \& Saunier, N. (2017). Cyclist deceleration rate as surrogate safety measure in Montreal using smartphone GPS data. Accident Analysis \& Prevention, 99, 287-296.

Strömberg, H. K., \& Karlsson, I. M. (2013). Comparative effects of eco-driving initiatives aimed at urban bus drivers-Results from a field trial. Transportation Research Part D: Transport and Environment, 22, 28-33.

Tapp, A., Pressley, A., Baugh, M., \& White, P. (2013). Wheels, skills and thrills: A social marketing trial to reduce aggressive driving from young men in deprived areas. Accident Analysis \& Prevention, 58, 148-157.

Tseng, C.-M. (2012). Social-demographics, driving experience and yearly driving distance in relation to a tour bus driver's at-fault accident risk. Tourism Management, 33, 910-915.

Vaiana, R., Iuele, T., Astarita, V., Caruso, M. V., Tassitani, A., Zaffino, C., \& Giofrè, V. P. (2014). Driving behavior and traffic safety: an acceleration-based safety evaluation procedure for smartphones. Modern Applied Science, 8, 88.

Washington, S. P., Karlaftis, M. G., \& Mannering, F. (2010). Statistical and Econometric Methods for Transportation Data Analysis. CRC press. 
Wood, J. S., Donnell, E. T., \& Fariss, C. J. (2016). A method to account for and estimate underreporting in crash frequency research. Accident Analysis \& Prevention, 95, 57-66. 
2020-01-30

Longitudinal jerk and celeration as

measures of safety in bus rapid transit drivers in Tehran

Khorram, Bahram

Taylor \& Francis

Khorram B, af Wahlberg AE, Kashani AT. (2020) Longitudinal jerk and celeration as measures of safety in bus rapid transit drivers in Tehran. Theoretical Issues in Ergonomics Science, Volume 21, Issue 5, 2020, pp. 577-594

https://doi.org/10.1080/1463922X.2020.1719228

Downloaded from Cranfield Library Services E-Repository 